\title{
Can Bailout Improve the Economic Welfare? A Structural Derivation of the Option Price
}

\author{
Masayuki Otaki \\ Institute of Social Science, University of Tokyo, Tokyo, Japan \\ Email: ohtaki@iss.u-tokyo.ac.jp
}

Received January 19, 2013; revised February 20, 2013; accepted March 18, 2013

Copyright (C) 2013 Masayuki Otaki. This is an open access article distributed under the Creative Commons Attribution License, which permits unrestricted use, distribution, and reproduction in any medium, provided the original work is properly cited.

\begin{abstract}
We developed a game-theoretic approach concerning the option pricing validity and tractability of which is ascertained by deriving the Black-Scholes formula. We also applied this approach to the welfare implications of the bailout policy. It is found that such a policy always worsens the economic welfare. This is because of the moral hazardous behavior of the buyer owing to the limited liability which is emphasized, for example, by Arrow [1] and Stiglitz and Weiss [2].
\end{abstract}

Keywords: Option Pricing by a Game-Theoretic Approach; Moral Hazard by Limited Liability; Welfare Economics Concerning Bailout Policy

\section{Introduction}

Whether bailout policies that are often adopted in financial crises improve the economic welfare or not is not self-evident. This is mainly because payoff functions of financial assets are not explicitly defined. This article provides the payoffs function of European call option definitively and considers a welfare implication of the bailout policy. As its corollary, we induce the BlackSholes [3] formula from the payoff functions.

Since the transaction of derivatives is generically a zero-sum game, an anticipated bailout policy does not rescue its traders. Once such a bailout policy is rationally weaved into expectations, it becomes a part of the value of the option. Henceforth, the bailout policy only partially improves investors' risk-neutral expected utility. However, the outsiders of the derivative transactions are heavily levied for financing such a policy, and thus, the economic welfare as a whole is always worsened by the policy.

The paper consists of three sections. In Section 2, we define the payoff functions of European call option and analyzes their properties. Section 3 derives the BlackScholes formula to ascertain the validity of our approach. Using obtained results, Section 4 solves the option price that is attached by the money brought about a bailout policy, and considers the macroeconomic welfare implication on the policy. In Section 5, we provide brief concluding remarks.

\section{The Model}

We consider an European call option the expiry date is $T$. An European call option is a kind of zero-sum game of which equilibrium concept is Stackerberg equilibrium. The strategy of a buyer (follower) is at what price she/he exercises the option. Seller's strategy (leader) is to offer the price of option and its exercise price.

As such, we obtain the following theorem.

Theorem 1. Let us denote the buyer's and seller's, payoff functions $V_{t}^{B}$ and $V_{t}^{S}$, respectively. They can be written as

$$
\begin{aligned}
& V_{t}^{B}(t: T)=E_{t}\left[\max \left[\mathrm{e}^{-r[T-t]}\left[S_{T}-X\right]-P_{t},-P_{t}\right]\right], \\
& V_{t}^{S}(t: T)=E_{t}\left[\min \left[\mathrm{e}^{-r[T-t]}\left[X-S_{T}\right]+P_{t}, P_{t}\right]\right],
\end{aligned}
$$

where $P_{t}$ is the option price at time $t, S_{t}$ is the stock price at the expiry date $T$, and $X$ is the exercise price. $E_{t}$ denotes the conditional expectation operator on the available information until time $t$.

To prove the above theorem, the following lemma is of use.

Lemma 1. Early exercise does not occur with probability one.

Proof.

Suppose that an early exercise occurs at time $\tilde{t}(t<\tilde{t}<T)$ with some positive probability. Then, 


$$
\begin{aligned}
& V^{B}(t: T) \geq \\
& \mathrm{e}^{-r[\tilde{t}-t]} \int_{\left[S_{\tilde{t}}-X\right] \mathrm{e}^{-r \tilde{t}-t]} \geq P_{t}}\left[S_{\tilde{t}}-X\right] \mathrm{d} \Phi\left(S_{\tilde{t}} \mid S_{t}\right)-P_{t}>0
\end{aligned}
$$

holds. $\Phi(\cdot)$ is the conditional cumulative distribution function of $P_{\tilde{\tau}}$ on $P_{t}$. The above inequality comes from the fact that an early exercise occurs because of the chance of the excess gain.

On the other hand, from (3), the seller's payoff function satisfies

$$
V^{S}(t: T) \leq P_{t}-\mathrm{e}^{-r[\tilde{t}-t]} \int_{\left[S_{\tilde{t}}-X\right] \mathrm{e}^{-r \tilde{t}-t]} \geq P_{t}}\left[S_{\tilde{t}}-X\right] \mathrm{d} \Phi\left(S_{\tilde{t}} \mid S_{t}\right)<0
$$

From (4), the seller's payoff becomes negative whenever an early exercise occurs with some positive probability, and hence such an asset never be provided. Accordingly, any early early exercise never occurs with positive probability.

\section{Proof of Theorem 1.}

From Lemma 1, since the call option is held till the expiry date $T$ with probability one, the values of call option become the expected discount values at $T$.

From Theorem 1, the following theorem holds.

Theorem 2. The equilibrium price of the call option $P_{t}$ is expressed as

$$
P_{t}=E_{t}\left[\max \left[\mathrm{e}^{-r[T-t]}\left[S_{T}-X\right], 0\right]\right] .
$$

To prove Theorem 2, the following lemma is of use.

\section{Lemma 2.}

$$
V_{t}^{S}(t: T)=V_{t}^{S}(t: T)=0
$$

holds.

\section{Proof.}

By adding up (1) and (2), we obtain

$$
V_{t}^{S}(t: T)+V_{t}^{S}(t: T)=0 .
$$

Since both $V^{S}$ and $V^{B}$ are non-negative, (6) holds.

Proof of Theorem 2.

Substituting (6) into (1) and (2), we can obtain (5).

\section{The Black-Scholes Formula}

In this section, we derive the Black-Scholes formula based on the above structural approach.

When the stock price $S_{t}$ follows the geometric Brownian motion with the drift $r$ and the instantaneous variance $\sigma^{2}$, by Ito's formula, it is well-known that the logarithm of the stock price $s_{t}$ follows the normal distribution, $\Psi$, the mean and standard deviation of which are $\left[\left[r-\frac{\sigma^{2}}{2}\right][T-t], \sigma \sqrt{T-t}\right]$. In addition, it can be easily shown by some elementary calculus that

$$
\begin{aligned}
& \int_{X}^{\infty} S_{T} \mathrm{~d} \Psi\left(S_{T} \mid S_{t}\right)=S_{t} \mathrm{e}^{-r[T-t]} \Phi^{S N}\left(z_{t} \geq-z^{*}\right), \\
& z_{T} \equiv \frac{S_{T}-S_{t}-\left[r+\frac{\sigma^{2}}{2}\right][T-t]}{\sigma \sqrt{T-t}}, \\
& z^{*} \equiv \frac{\ln \frac{S_{t}}{X}+\left[r+\frac{\sigma^{2}}{2}\right][T-t]}{\sigma \sqrt{T-t}},
\end{aligned}
$$

where $\Phi^{S N}$ is the standard normal cumulative distribution function.

Since the logarithmic value $s_{t}$ of the stock price $S_{t}$ follows $N\left(\left[r-\frac{\sigma^{2}}{2}\right][T-t], \sigma \sqrt{T-t}\right)$,

$$
y_{T} \equiv \frac{s_{T}-s_{t}-\left[r-\frac{\sigma^{2}}{2}\right][T-t]}{\sigma \sqrt{T-t}}
$$

also follows the standard normal distribution $\Phi^{S N}$. Let us define the critical value $y^{*}$ as

$$
y^{*} \equiv \frac{\ln \frac{S_{t}}{X}+\left[r-\frac{\sigma^{2}}{2}\right][T-t]}{\sigma \sqrt{T-t}} .
$$

Substituting these results into (5), we obtain

$$
P_{t}=S_{t} \cdot \operatorname{Pr}\left(z_{T} \geq-z^{*}\right)-X \cdot \operatorname{Pr}\left(y_{T} \geq-y^{*}\right) .
$$

Finally, by the symmetry of the normal standard distribution,

$$
P_{t}=S_{t} \Phi^{S N}\left(z^{*}\right)-X \Phi^{S N}\left(y^{*}\right) .
$$

This is the Black-Scholes formula.

\section{The Welfare Economic Implication of the Bailout Policy}

Usually, the validity of the bailout policy is judged from the view of income distribution: whether it is legitimate or not for redistributing incomes from tax payers to failed speculators. However, instead, we here deal with the aspect of efficiency of the bailout policy. This is not a self-evident problem because some parts of money of an anticipated bailout will be consumed to stimulate the zero-sum game within the option trading. This is due to the fact that the bailout guarantees the minimum return for buyers and causes a kind of moral hazard which comes from the property of limited liability. Thus, not all money poured by the bailout can be used for the compensation for the capital loss, and thus, the effect of the bailout policy is rather mitigated. Consequently, as 
we shall precisely discuss below, the bailout policy conversely worsens the economic welfare. Besides advancing the disparity of income distribution, the bailout policy harms the people's well-being.

To endorse the above discussion, let us define the payoff functions under a bailout policy. The assumed bailout policy is as follows: at the expiry date $T$, money, which is levied on outsiders and amounts to $M$, is transferred to the losers (sellers when the option is exercised/buyers when not exercised).

We must note that the effective exercise price rises from $X$ to $X+M$. This is because the bailout money $M$ becomes the lower bound of seller's revenue, and thereby the option is exercised only when $S_{T}-X \geq M$.

$$
\begin{gathered}
V_{t}^{B}(t: T, M) \\
=E_{t}\left[\max \left[\mathrm{e}^{-r[T-t]}\left[S_{T}-[X+M]\right]-P_{t}, \mathrm{e}^{-r[T-t]} M-P_{t}\right]\right] \\
=\mathrm{e}^{-r[T-t]}\left[\int_{X+M}^{\infty}\left[S_{T}-[X+M]\right] \mathrm{d} \Phi\left(S_{T} \mid S_{t}\right)\right. \\
+M \Phi(X+M)]-P_{t} .
\end{gathered}
$$

Corresponding to (9), the seller's payoff function becomes

$$
\begin{aligned}
& V_{t}^{S}(t: T, M) \\
& =P_{t}-\mathrm{e}^{-r[T-t]} \int_{X+M}^{\infty}\left[S_{T}-[X+M]\right] \mathrm{d} \Phi\left(S_{T} \mid S_{t}\right) .
\end{aligned}
$$

Note that when $S_{T}-X<M$ and the option does not exercise. Since there is no loss in the seller side, there does not appear $M$ corresponding to such a case in the above equation.

Summing up both sides of (9) and (10), we obtain

$$
\begin{aligned}
& V^{B}(t: T, M)+V^{S}(t: T, M) \\
& =\mathrm{e}^{-r[T-t]} M \Phi(X+M)<\mathrm{e}^{-r[T-t]} M .
\end{aligned}
$$

Since the actual total sum of money poured into the bailout is $\mathrm{e}^{-r[T-t]} M$, (11) implies the social cost of bailout exceeds the benefit from such a policy. Consequently, we reach the following important theorem.

Theorem 3. The bailout policy always harms the economic welfare.

The background of the above theorem is as follows. The option is exercised with probability $1-\Phi(X+M)$. In such a case the transaction of the option attached the bailout policy becomes a zero-sum game because the exercise price increases by $M$, and there is no substantial effect of the bailout policy. In other words, a kind of moral hazard owing to the limited liability occurs in the buyer's side. Since the value function of seller is passively defined in accordance with the buyer's action, an increase in the effective exercise price enlarges the seller's loss and there is no social gain in such a case.

Finally, we solve the equilibrium option price depending the Black-Sholes formula. There is an indeterminacy concerning the pricing, because the game is not zero-sum and the values of the payoff functions differ in case of the bailout policy. Thence we deal with the case that the competition among sellers is under strain, and there is no surplus for them (i.e., $\left.V^{S}(t: T, M)=0\right)$. Then, applying the Black-Scholes formula to (10), we obtain

$$
\begin{gathered}
P_{t}=S_{t} \Phi^{S N}\left(z_{M}^{*}\right)-[X+M] \Phi^{S N}\left(y_{M}^{*}\right), \\
z_{M}^{*} \equiv \frac{\ln \frac{S_{t}}{X+M}+\left[r+\frac{\sigma^{2}}{2}\right][T-t]}{\sigma \sqrt{T-t}} \\
, y_{M}^{*} \equiv \frac{\ln \frac{S_{t}}{X+M}+\left[r-\frac{\sigma^{2}}{2}\right][T-t]}{\sigma \sqrt{T-t}} .
\end{gathered}
$$

Note that $V^{B}(t: T, M)=\mathrm{e}^{-r[T-t]} M \Phi(X+M)>0$, and hence, buyers are ready to accept such an offer price. Thus, the trading is surely settled.

\section{Concluding Remarks}

We have succeed in deriving the Black-Sholes formula from the payoff functions within a some kind of zerosum game. Such a structural approach enables to apply the formula to more general case than in the original paper. The most relevant case is that a bailout policy is weaved into investors' rational expectations. Once such a policy is anticipated, the price of option becomes dear and investors' behavior becomes more bullish since the bailout policy eliminates the loss when the speculation fails.

Since the transaction of derivatives is generically zerosum game, the bailout policy never improves the economic welfare. Indeed, when we take in account that the financial source of the bailout policy is levied from another economic agents, the economic welfare is surely lowered by such a policy.

\section{REFERENCES}

[1] K. J. Arrow, "Uncertainty and the Welfare Economics of Medical Care,” American Economic Review, Vol. 53, No. 5, 1963, pp. 941-973.

[2] J. E. Stiglitz and A. Weiss, "Credit Rationing in Markets with Imperfect Information,” American Economic Review, Vol. 71, No. 3, 1981, pp. 393-410.

[3] F. Black and M. Scholes, "The Pricing of Options and Corporate Liabilities," Journal of Political Economy, Vol. 81, No. 3, 1973, pp. 637-659. doi:10.1086/260062 